\title{
Breaking the Triple Lock: Further education and transformative teaching and learning
}

This is a draft of a published paper.

Citation: Duckworth, V. and Smith, R. 2018. "Breaking the triple lock: further education and transformative teaching and learning", Education $\mathcal{E}$ Training, 60: 6 pp. 529-543. https://doi.org/10.1108/ET-05-2018-0111

This material is subject to copyright

\section{Abstract \\ Purpose}

This paper explores data from the UCU Further Education in England: Transforming Lives $\mathcal{E}$ Communities research project and through this develops a distinctive, theorised conceptualisation of transformative teaching and learning (TTL).

\section{Design/methodology/approach}

The research used an approach grounded in critical pedagogy utilising digital methods, including video'd interviews, to collect narratives from learners, teachers, family members and their communities from colleges across Britain.

\section{Findings}

Within a context in which there are structural pressures militating in favour of instrumentalising students in further education, TTL offers a way of theorising it as a transformative critical space that restores students' hope and agency. The research provides evidence of how further education offers this "differential space" (Lefebvre 1991) and subverts the prescriptive, linear spaces of compulsory education. While productivist approaches to vocational education and training support ideologies that legitimate prescribed knowledge, reproducing inequality and injustice through the practices employed (Ade-Ojo and Duckworth 2016, Duckworth and Smith 2017b), TTL shifts to a more holistic approach, achieving a different level of engagement with learners.

\section{Practical implications}

The findings suggest that the TTL lens is a way of focusing on the dignity, needs and agency of further education students. The lens allows us also to identify how the existing structures associated with funding and marketisation can undermine the potential of TTL to activate students' agency through education.

\section{Originality/value (mandatory)}

Extending on existing literature around transformative learning, and drawing on a range of theoretical frameworks, the article formulates a new, contextually specific conceptualisation of transformative teaching and learning. 
In this paper we will present data from the UK Further Education Transforming Lives project (Duckworth and Smith 2018) to provide a sharp focus to theorise what shapes transformative teaching and learning (hereafter TTL) in further education. After providing an overview of the current further education context in the UK, we will explore a range of data from the project and discuss how TTL can be a powerful and meaningful framework for conceptualising teaching and learning that prioritises the agency, needs and the dignity of students.

Despite historically embracing a wide range of accredited and non-accredited courses for adults and young people, over the last quarter century, further education in the UK has been increasingly positioned by successive governments as a route for 'vocational' courses suited to learners aged 16-19 (Wolf 2011, Fuller 2011) who are often adjudged not to be 'academic'. Within a competitive framework, this presents further education as a route for learners who at 16 have failed to achieve the national benchmark of attainment which was aligned to 5 GCSEs at A*-C (DfE 2015) but has recently shifted to value-added or 'Progress 8' (DfE 2017). This reductive view of the great breadth of courses offered by further education providers is anchored in the growth of a neoliberal skills discourse that sees further education almost exclusively in terms of the production of human capital for employers (See Becker 1993). Human capital theory seeks to connect educational systems to neo-liberal economic development strategies, positioning knowledge and learning as modes of capital and economising and commodifying the potential of human beings to contribute to productivity in employment contexts. As such human capital connects with the notion of the 'knowledge economy' (Ball 2017) in which education is tasked to provide a flexible, adaptable and skilled workforce to make countries competitive in the globalised economy. This commodification of education largely occludes broader concerns and purposes particularly those connected to social justice and equality. Within such an instrumentalist perspective, further education is seen as provision stratified through its offer of catering for low levels of choice and agency.

It is possible to chart this instrumentalist ideologically driven view of education that harnesses it to business and commerce back to James Callahan's Great Debate speech of 1976 (Smith and O'Leary 2013: 245). Instrumentalism is clearly visible in New Labour's Third Way policy agenda (Petras 2000) and its discursive attempt to connect market capitalism with social justice. This emphasis is captured succinctly in the phrase 'the Skills Revolution' (Pring 2005: 218) and is exemplified in policy documents like The Learning Age document which proclaims: 'Learning will be the key to a strong economy and an inclusive society' (DfEE 1998: 3). Four years later, another key government policy document, Success for All, offers another example of a similar syncretism, stating how the government's goals should be 'social inclusion and economic prosperity' (DfES 2002: 9). 'Skills' appears to be a term whose meaning is strongly influenced by conceptions of social class and for that reason is important in any discussion about further education. When connected to educational discourse, use of the term skills operationalises education as a conveyor belt for the production of a flexible, adaptable and 'skilled' workforce to make countries competitive in a globalised economy. 'Employability' - currently a trending education policy term - is another example from a reductive lexicon that conceptually connects education to a 'readiness to work' (Boden and Nedeva, 2010, 49-50). 
More recent policy documents continue these themes. Fixing the foundations: boosting Britain's productivity (BIS 2015), a conservative-led coalition government report, illustrates a continued adherence to a view of education as, primarily, an aspect of human capital development.

Over the last century, productivity growth has gone hand in hand with rising human capital, as more people have become educated, and to a higher level. However, the UK suffers from several weaknesses in its skills base that have contributed to its longstanding productivity gap... Results from the OECD show that England and Northern Ireland are in the bottom four countries for literacy and numeracy skills among 16-24 year olds. (BIS 2015: 23)

This neoliberal imaginary, structured by a league table of national economies, provides the backdrop for most recent further education policy. In response to these perceived "weaknesses in (the) skills base" and the "productivity gap", Fixing the Foundations provides a platform for further intervention. In that respect, the government re-launch of apprenticeships identifies it as the primary vehicle for bridging the gap between education and work for a large section of the nation's young people. This latest version of apprenticeships embraces a more work-based learning approach with employers very much 'in the driving seat' (BIS 2015, 23-26) as regards content and the focus on relevant skills. As such it also signals a diminution in the role of colleges and other further education providers.

Globalisation, competition and rapid progress of technology have contributed to shifts in educational policy-making. The current plans for the UK remain ambitious: in 2009, the UK Commission for Employment and Skills (UKCES) stated:

It is our ambition to be one of the top countries in the world - for jobs, for productivity and for skills. A World Class economy, built on World Class skills, supporting World Class jobs and businesses. We should aim to be in the top quartile of OECD countries in all three - jobs, productivity and skills - by 2020.... Our future prosperity depends ultimately on employment and productivity: how many people are in work and how productive they are when they are in work. Skills are essential to both. If we are to become World Class, we must raise our game to match the productivity, skills and jobs of the best. (UKCES 2009: 6)

The passage above provides strong evidence of the 'disenchantment of politics by economics' that Davies (2014) identifies as a quintessential ideological tenet of neoliberalism. Ethical scruples are pushed aside and political considerations are neutralised by the common-sense assertion of the importance of government policy that focuses on the hegemonic triad underpinning a 'World Class economy': jobs, productivity and skills.

In relation to the notion of transformative teaching and learning - the focus of this paper the discursive lexicon that includes terms such as skills, productivity and employability blur the complexity of the relationship between vocational qualifications, learners' intentions, destinations and actual employment opportunities in the jobs market. In addition, they bypass the broader debate around the different purposes of education (see e.g. Biesta 2010). One aspect of the Transforming Lives project involved exploring the ways in which further education offers TTL opportunities that shift beyond such dominant 'productivist' notions of the education / work relationship which have failed many marginalised people and move towards a transformative paradigm which instead draws its values from a libertarian, 
egalitarian and social justice base which challenges the hegemonic discourses and practices which are underpinned by oppressive and unjust drivers.

\section{The current further education context in England}

Arguably, further education providers have borne the brunt of the operationalisation of this skills discourse. Further education seems particularly vulnerable to the influence of the global knowledge production and policy-think of international organisations like the Organisation for Economic Co-operation and Development (OECD). Through both PIAAC (the Programme for the International Assessment of Adult Competencies) and PISA (the Programme for International Student Assessment) - further education becomes 'measurable' through what Grek calls the 'new technology of the governance of the European education space through indicators and benchmarks' (Grek 2008: 215). Despite the ideological dominance of this neoliberal skills discourse in further education policy which reifies it as a key part of a national skills 'delivery' mechanism, there has been a reduction in government funding for colleges in the last decade. This is in large part due to the adoption by the Coalition Government of 'austerity' measures in the period 2009-14 and further education's vulnerability to these as a consequence of incorporation (Smith 2017). During this period, funding for adult courses was reduced by around 35\% (UCU 2015) while at the same time there was a redirection of finance towards Apprenticeships. What hasn't changed significantly is a longstanding competitive funding environment (Smith 2007,43) that has been heavily criticised for leading to 'spoon-feeding', 'gaming' and a narrowed curriculum (O'Leary and Smith 2012, Smith and O'Leary 2013, Wolf 2011).

The Transforming Lives research project sought to gather learners' narratives, and to understand these against the backdrop of wider socio/economic/political and historical contexts (Goodson \& Sikes, 2001, Duckworth 2013, Duckworth and Ade-Ojo 2016; Duckworth and Smith 2016, 2018). The research cut across the grain of the skills policy discourse providing evidence that despite the instrumentalisation of the curriculum in further education, transformative teaching and learning is (still) taking place. Recognizing the power of education to reproduce rather than challenge social inequality offers a frame for understanding learners' narrative accounts of their educational and personal journey against the backdrop of the structural inequalities they have faced. Importantly, while these narratives might connect with employment and/or career progression, they are not defined by this. Rather, they centre on personal development, the enhancement of student agency and hope and they are underpinned by the primacy of human dignity and the flow of this into students' families and communities. In short, they work against the instrumentalist turn and in the place of the 'choice' offered by market fundamentalist policies, offer a choice rooted in students' enhanced agency.

\section{Theoretical framework}

The key conceptual tool we aim to develop in this article is a contextualised concept of transformative teaching and learning (henceforth TTL) environments. Other literature (see Lavender et al 2018) discusses the significance of transformative learning theory and the critical debate the concept has engendered. In this article, we will outline the key aspects of TTL environments and ground them in the current context of further education as outlined above. 
A starting point for our elucidation of the term TTL is that it describes an interactive, interdependent and dynamic relationship between students and other students, and students and their teachers. Frank Coffield provides a useful point of reference here:

For me, teaching and learning are not two distinct activities, but intertwined elements of a single, reciprocal process, or, if you like, the two sides of one coin; perhaps they could be described as a double-sided, interactive process which transforms both tutor and learner. (Coffield, 2008: 8)

There are a number of reasons why this insistence on the interconnection between teaching and learning resonates with the Transforming Lives research. First, by including teachers, it emphasises their role in establishing an environment or space and set of relationships in which students can validate their socially situated knowledge and value the knowledge generated from their lived experiences. Through the concept of TTL, we also seek to avoid locating the motor of transformation (only or primarily) within individuals, rather than seeing it as an effect that is consciously produced through interaction between teachers and students. This aspect is highlighted by the relation of 'care' on the part of the teacher that was also a repeated theme in the data. The notion of 'care' (Feeley 2007) is extended to 'dialogic care' and re-claimed as a tool for this and mutual respect. The kind of care underpinning TTL is not patronising or passivizing but instead is orientated towards fostering student engagement and autonomy. It was a principle that underpinned the success of TTL and flowed into the private domains of the learners' lives. Dialogic care is important because young people and adults entering further education spaces may hold a deficit view of themselves as learners as a direct consequence of their experiences of schooling. But in addition to overcoming the barriers associated with the experience of being labelled, we argue for the importance of reasserting the collective and social aspects of learning - a feature of further education that distinguishes it from schooling.

The research we draw on is less focused on producing a definition of transformative learning that centres on the effects on individual learners or on measuring such phenomena (if they can be measured). Instead the starting point of this research was an awareness that despite the turmoil produced by cyclical policy intervention and a funding model that incentivises 'gaming' by providers, some students continue to experience learning in further education as a positive social experience that enhances their agency as individuals going forward in their lives. While the work of Mezirow (1990) and Illeris (2013) among others seeks to elucidate a set of universal principles that underpin transformative learning, our work sees context as a vital component in any understanding of what transformation might mean. A legitimate question might then be: why are TTL experiences necessary here and now? Whilst it is beyond the scope of this article to explore the problematic nature of the agestaged tyranny of achievement matrices that structure schooling in the UK (Mansell 2007), the negative, stigmatising impact it had had on many of the participants was a salient research finding. Following on from that, one key aspect of TTL is a recognition of this and a strong emphasis on building confidence to renew learning identities as a consequence of the 'symbolic violence' many students have experienced in their schooling.

The concept of symbolic violence originates in Bourdieu and Passeron (2013). They write about the symbolic system that education draws on to inculcate and impose meanings on learners. They see education as imposing a standard culture whose values reflect the social 
structure and the power relations that underpin it. In other words, in a socially unequal society, education perpetuates inequality and a stratification of individuals in a way that serves to replicate existing social inequalities. They argue that there is a 'twofold arbitrariness' in pedagogic action (ibid. 5-6). The first arbitrary is the power underpinning pedagogic authority; the second is the 'cultural arbitrary' that the pedagogy seeks to impose. Pedagogic action can only take place with pedagogic authority which they see as:

a power to exert symbolic violence which manifests itself in the form of a right to impose legitimately (which) reinforces the arbitrary power which establishes it and which it conceals. (Bourdieu and Passeron 2013: 13)

Pedagogic action for Bourdieu and Passeron constitutes symbolic violence because it entails the imposition of arbitrary meanings and cultural values on learners. But while Bourdieu and Passeron dismiss the possibility of a critical pedagogy which foregoes symbolic violence, seeing no pedagogic action as 'culturally free' (ibid. 17), their model is very transmissive. It adopts a view of educational experiences as experiences in which learners are recipients rather than co-constructors of meaning. Bourdieu and Passeron see education as affirming the cultural background of some children while delegitimising that of others. In this sense pedagogic action imposes a recognition of the legitimacy of the dominant culture on members of dominated groups, classes and individuals, but it also imposes on them by forcing on them a recognition of the illegitimacy of their own culture.

So how is it possible to theorise TTL in the light of Bourdieu and Passeron's thinking on symbolic violence and the 'twofold arbitrariness of pedagogic action'? We would argue that the twofold arbitrariness of pedagogic action at the heart of the notion of symbolic violence is specifically addressed in TTL environments. The first arbitrary: the power underpinning the pedagogic authority is addressed through the egalitarian relations that teachers strive to establish. The second aspect, the 'cultural arbitrary' that pedagogic action seeks to impose is addressed through the inclusion and (even) centrality of learners' biographical experiences in the curriculum. Evidence from learners and teachers in the research repeatedly returns to these characteristics; and learners' narratives in particular repeatedly contrasted TTL environments with prior educational experiences in which they felt judged and labelled in deficit terms.

While the theoretical perspectives offered above focus on the classroom interactions, we also think it is important to clarify the way symbolic violence operates through the abstract notion of the "FE sector". It would be inaccurate to claim that experiences of symbolic violence in education are confined to schooling. Indeed, arguably, the current further education system in the UK is as or more susceptible to the hegemonic and structuring ideas that impose meanings and curricula on students in ways that do not best serve their interests. One way of viewing the way symbolic violence plays out in further education is through student objectification - a concept we would like to develop here. There are at least three forces of objectification - a triple-lock of symbolic violence - that students in further education can be said to be (potentially) subject to. The first layer of objectification is located in the 'skills' discourse outlined earlier. While not singling out or categorising individuals, this neoliberal ideological weltbild provides a common-sense framework or understanding further education as human capital production (as elucidated in UKCES 2009 above), an understanding that is inherently demeaning of further education students. 
The second layer of the triple-lock is more substantial and structural in the sense that it is reified by the current qualifications framework and the expectations, ways of thinking and student learning trajectories that this gives rise to. This second layer of objectification resides in the qualification framework that enforces a binarist perception of young people as being either 'academic' or 'vocational' (Payne 2010). This is also a feature that has been reinforced by the stratification that marketization naturalizes. Under this layer of objectification, particularly within a policyscape that seeks to represent further education as solely or primarily focused on vocational learning, further education students are 'classed' (Thompson 2010) and structurally disadvantaged and potentially objectified as low achievers.

The third and final layer of the triple-lock in further education is a further consequence of the competitive marketization that has emerged in further education. A key aspect of the incorporation of colleges in 1993 was that it introduced a transactional aspect to the relations between students and providers. While this supposedly privileged students through their choice as 'consumers', a more evident and significant effect was to incentivise teachers and managers in further education to view the recruitment of students in funding terms, as a 'bums on seats' exercise. Taking this triple-lock of objectification into account, it seems miraculous that TTL is taking place at all in further education settings, but our research provides evidence that it is.

\section{Connecting critical pedagogy to research methodology}

Before moving on to explore some of our data we will first outline the methodological approach we adopted for the study. This grew out of the background of both researchers in critical literacy education (Freire 1995, Breunig 2005). That informed the care that we took to frame research conversations (we use this phrase in preference to the term 'interviews') to foster a sense of equality between the participants and the researchers. These research conversations usually took place in the further education setting where participants were studying. Reciprocity was also important: we shared our own stories to establish openness and informality acknowledging that the research aspect of what we were doing was one part of a broader social encounter.

The research conversations provided participants with an opportunity to share their narratives through the format of video. These video narratives were shared publically through a project website. Rather than the stories being hidden or shameful, the project participants reclaimed them as stories of success while recognising the structural inequalities that they challenged and resisted to take agency in their lives and communities (Duckworth 2013, Duckworth and Smith 2019). The project participants, who may have been constrained by factors such as class, gender or ethnicity, benefitted from the telling of their stories which contributed to a social capital, by proxy, in that they and the communities they belonged to could draw on the accounts to motivate them to take their own learning journeys forward.

Pink (2007: 96-7) discusses how using a video camera can disrupt the relationship between researcher and participant. The loss of eye contact when the researcher peers into the viewfinder can heighten the participant's awareness of 'being filmed'. We were able to avoid this in our project; the autofocusing equipment, with its large screen display, enabled us to 
set up the camera on a tripod, start recording and then to start the conversation, occasionally checking and refocusing. Once again, the emphasis was on foregrounding the informal and safe nature of the research space. The research conversations were purposefully affirmative of participants' achievements and the agency they had rekindled through learning. There is a connection here with critical pedagogy: our research practice positioned itself in such a way as to extend the affirmative regard that we see as underpinning transformative teaching and learning experiences. In other words, the conversations sought not just to record participant narratives but to interact in an affirming way with the people recounting them.

The research conversations provided opportunities to enact and document what Tedder and Biesta refer to as 'narrative learning':

By narrative learning we mean that learning can take place as a result of articulating stories from one's life, through the process of talking about and reflecting on life experiences... (Tedder and Biesta 2009: 89)

In this way, the research conversations were positioned as an extension of the TTL experiences that were the central concern of the project. The project data, a series of rich narratives from learners, teachers, employers and learners' family members, were shared via a project website. A Youtube channel ${ }^{1}$ and twitter account ${ }^{2}$ were further features of a multifaceted digital platform that, together, interacted to broaden the reach of the project and to house a critical space which garnered further contributions in the form of written accounts, photographs and artefacts from a growing project audience.

The digital platform was the catalyst to what we describe as virtually enhanced engagement adding to the data in an organic way and extending the influence and meanings of the project in the public domain - for example by connecting the researchers directly with a key policy maker. With the consent of participants, we shared the narratives across the public domain. The website became an interactive vehicle for the co-construction of a virtual community bringing together learners, teachers, academics, activists and policy-makers. Project participants' voices in this way were able to reach out and cross different domains to challenge stereotypes and unsettle hegemony. The first year of the project culminated in a conference that brought together participants from across the country to explore the research themes across the breadth of further education provision.

We adopted a thematic approach to the data analysis but our approach deviated markedly from the kind of linear model with distinct stages as suggested by Braun and Clarke (2006). For example, as researchers with a body of existing work on further education, we understood that this experience positioned us both historically and politically in relation to the data. The notion of 'bracketing' (for a critique see Thomas and James 2006: 782) or a 'pure' inductive, data-driven approach was inappropriate. The positionality (Lather 1991: 6) of the researcher seems to us to preclude a 'pure' inductive approach. Thus we brought to the data a set of theoretical tools which originated from the literature on transformative learning. An example might be when participants talked about being 'labelled' at school; this statement connected with the notion of symbolic violence that we already saw as a

\footnotetext{
${ }^{1}$ https://www.youtube.com/channel/UCkDeirtGCmeBs361BgibXnA

$2 @$ FEtransforms
} 
feature of the further education context in which a 'second chance' is offered to people with negative experiences of schooling.

The analysis was also more iterative and organic than is suggested by a staged model. The pattern we followed connects closely to critical reflective practice (Brookfield 2005) in which (in the short term) events were convened and then reflection took place. Theming often began immediately following a research conversation as we picked out instances where participants' meaning-making resonated with or built upon interpretations of data already gathered. Familiarisation with the data in terms of immersion and review was preceded by this discursive 'spotting' of nuggets of data. These nuggets were sometimes moments in the conversation when the participant said something that re-contextualised existing interpretations in new or unexpected ways.

Typically, the data was gathered in research visits where four or five individuals were seen. Thus, the theming phase had no distinct temporal boundaries as different research visits yielded different themes. We found the distinction between semantic and latent themes (Braun and Clarke 2006: 84) useful. Semantic themes were often those that were identified during and immediately after the research conversation. These initial thoughts were then developed through the immersive process of editing each video and at this stage latent themes were also identified. The captions that we have added to each video became a way of focusing the analysis. These became a way of signalling these significant concepts that connect the different research conversations. Each video with its preliminary analysis was sent to participants for additional comment and to sound out the initial analysis. In this way, each research conversation became a testing ground on which existing analytical tools were applied and their explanatory power re-evaluated. In that sense, our analytical approach sidestepped the binarism of either deductive or inductive thematic analysis. Different research conversations yielded familiar themes but also required us to respond to the 'surprises' that are familiar from reflective practice frameworks (e.g. Brookfield 2005, Schön 1983) There was also a longitudinal analytical arc as, across different events, the analysis developed through a de-contextualising and re-contextualising cycle. In this way, over two years of data gathering, the thematic analysis became richer as we engaged with new data and related it to earlier conversations. The choice of what to foreground in each video and then, often in a different way, in the writing that followed, required careful consideration. Having a broader audience beyond the academic research community, the videos can be regarded as attempts to provide accessible (and for us strategic) narratives offering key insights into TTL.

\section{Ethics}

The use of video and the project website involved important ethical consideration. The project was scrutinised and passed by the Ethics Committees of both researchers' HEIs. We adhered closely to the BERA ethical guidelines (2011) throughout the project offering all participants anonymisation at the recruitment stage, but as the focus was on the transformative qualities of their educational experiences, most wanted their real names to be used. Each video was edited and then shared with the participant prior to publication. Reedits were undertaken at the participant's request. The emphasis throughout was on maintaining their dignity while presenting their stories in their own words. The stories of many were closely connected to particular colleges and even specific teachers. Where these 
were mentioned, we also sought permission to include these. The publication of videos on Youtube raised the issue of the need to remain aware of public comments and to respond, edit and delete these where appropriate.

\section{Findings i) Schooling, further education and symbolic violence}

As suggested already, TTL pedagogies are a response and an antidote to the 'symbolic violence' (Bourdieu and Passeron 2013) experienced by many learners in their compulsory education. The power of symbolic capital and what is valued and why in different fields offers an insightful avenue of enquiry into the experiences of the learners in this study. It allows for a deepening of our understanding about notions of symbolic violence the participants had been subjected to in their schooling and its impact on their identity and lives.

The relationship of symbolic violence to learning and the impact it had on participants' sense of themselves as effective and successful learners emerged strongly from the data. A large number of the participants talked about their negative experiences of schooling. Sometimes this coincided with undiagnosed dyslexia (e.g. Anita, Herbert), the impact of external forces connected to family (e.g. Kate) or a feeling of being overlooked or not understood (e.g. Nyomi, Chaima, Jacqui). In other cases (e.g. Rithenella, Marie and Adam) a strong sense of labelling emerged. The symbolic violence that the learners had experienced was often hidden because it triggered feelings of shame in the individual. Adam provided a powerful representative example of this. Adam was a sixteen year old who was excluded from his local school and explained how one reason for this was that he had anger management problems:

In school I was getting angry quite a lot. I was punching walls... I used to think I was dumb all the time in school. I had no hopes at all....

The knock-on effects for Adam's family and home life were significant. His mother described how she received phone calls every day and sometimes had to leave work in order to pick her son up early from school. Adam's sense of being 'dumb' and ignored was, in his mind, connected to teachers' labelling him as coming from a particular estate with a 'reputation': this created negative expectations that meant his identity as a learner was severely compromised:

I was in a lesson and I was there with my hand up asking for help and there was another person with their hand up asking for help. I'm the naughty one and he was a good lad... So (the teacher) went straight to him and then another person put their hand up and then another person even though I had my hand up. And he kept going round and round until after nine people then he come to me. And that was why I was getting angry... Everyone just looks at you and they think Oh yeah... They judge a book by its cover and you shouldn't do that.

In Adam's story, symbolic violence is observed as an outcome of the way the teacher relates to and interacts with the learner. As with another participant, Anita - who talked about being put 'in a box', symbolic violence takes the form of an ongoing assessment of 'ability' 
that shapes social interactions between teacher and learner. The educational relationship becomes characterised by a teacher's judgemental position and regard towards the student.

\section{Findings ii) TTL environments: evidence from the research}

Data from the project provided a range of evidence about the different conditions that, work together as constituent parts of TTL environments. One key aspect of a learning environment that favours TTL is the way in which the curriculum relates to the learners' biographies. For most learners, this was as simple as being accepted for who they were:

My self-esteem and confidence wasn't what it was when I was eighteen. (Now) I'm comfortable in my own skin. And that's something to do with equality. And people at Northern College accepting you for you... And just that right to speak without being interrupted. I found that, like, so powerful. And being really listened to as well. (Clare)

This theme of acceptance and affirmation was echoed by others, sometimes it was expressed in terms of the 'feel' of the learning space, sometimes it was connected to the relationship that was formed with the college staff. Anita, a learner who went from 'dead-end jobs' to a social work qualification expressed this in these terms:

My tutors are the ones that have got me here. They've got me this far. I don't know where I would have been without Judith and Margaret... They didn't push me, they encouraged me. They never once doubted me. They encouraged and they made me grow. Through that, I've been able to inspire my kids.

Here we also see the impact of TTL for students and their families: its intergenerational ripple effect. Anita's renewed hope and agency has had the knock-on effect of providing an environment in which her children feel motivated and able to connect their educational achievements to their becoming-biographies. It is revealing to contrast this with the assumptions about learner agency within the neoliberal skills discourse. To return to the image used in the Building the Foundations policy document (BIS 2015):

Professional and technical education provision... needs to be refocussed to deliver the higher level skills that employers need. Strong institutions are needed to support this ambition.... The government will... invite some colleges to become prestigious Institutes of Technology to deliver high-standard provision at levels 3, 4 and 5... Institutes of Technology will be sponsored by employers, registered with professional bodies and aligned with apprenticeship standards. The government will empower National Colleges, Catapults, and elite professional institutions to design each route, alongside employers and professional bodies. (BIS 2015, 25-26)

This passage comes from a section of the document entitled Putting employers in the driving seat. The overview here is of policy that aims to change not just course content but also the structures and cultures of colleges - better to meet the needs of employers. Notable by its absence is any mention of learners' needs, hopes or requirements. Evident here is the first layer of the triple-lock of objectification. The inference is that employers' and the nation's needs take precedence.

In curricular terms, this position is in direct opposition to the kind of "differential space" (Lefebvre 1991) that characterises the TTL environment. A distinctive feature of the 
conceptualisation of TTL that emerges from the study is that learning is not a measurable process delimited by distinct parameters in time-and-space. Instead, learning is an aspect of consciousness that bleeds between moments in time, relationships, action, self-image and space. Above all, the conditions that make it possible to take place are social. As such, TTL necessitates a curriculum in which the learner takes a central position, certainly at the start of a course and then, as autonomy and confidence grows, less pervasively. The research evidence on this is encapsulated well by one of the teacher participants. In our research conversation, Jez talked about his passion for teaching Level 1 and Level 2 Business students. The learning environment Jez sought to establish in the classroom overturned the low expectations that many of his students had brought with them from their prior educational experiences. A principal technique Jez used was to foster autonomy. Interestingly, he uses the same metaphor as the Building the Foundations document.

I don't see it as me and them... We are all one... we work together, so when they are driving their own bus, initially, I'm driving it. I'm showing them where the gear stick is, I'm showing them where the steering wheel is. But as their confidence builds, as they get more familiar with... the expectations... I place on them, they take over the reins, and they start driving the bus. So they dictate which way they want the course to go on, what units they want to do within the course... that's a huge step for some of the under-privileged learners that I come across - to be given that power.

The egalitarian conditions of TTL evidenced here do not hinge on the teacher ceding authority in the classroom. But rather, they reside in her/him using authority to establish a particular environment in which a traditional uni-directional, transmission-orientated power dynamic is replaced by one which, in Stenhouse's sense, is more differentiated (Stenhouse 1981: 107). Importantly, it is also collective and requires learners to take on a role of responsibility in making decisions about the curriculum. Whether or not this meets the 'needs of employers', appears to be beside the point as Jez models the kind of fostering of agency that employers might be expected to provide.

Another participant, Dean, offered an insight into how a TTL environment could meet an employer's needs while also acting as a catalyst for personal and professional development. In Dean's case, his employer liaised closely with the college to ensure a construction curriculum that was appropriate. But the employer relied absolutely on the expertise and the affirmative approaches adopted by the college teaching staff. For Dean, attending college also meant overcoming the significant barrier of a lack of self-confidence.

Given the opportunity to further myself, that's a no brainer. But then coming to college, that first day, I was like: I'm not sure I can do this.... It's changed me. I can do things. I am capable... The first day I started I had no computer skills... Now I feel like I've got a bit of respect. It's definitely life-changing... Even with the kids, I went to parents' evening... I ended up chatting (to the teacher) more about me than about (my daughter).... I've been promoted to be site manager. It's been an amazing turnaround.

Simon, the managing director of a construction company and Dean's employer talked about the importance of 'growing' his own talent. By this he meant positioning learning at the heart of his company. This involved him in developing a holistic educational experience with a local college that blurred the boundaries between learning spaces and workplace. The apprenticeship course that Dean was undertaking was dependent on Simon's personal 
commitment as an employer to his employees. Simon saw construction as a vocation and a career with opportunities for personal growth and the development of skills and knowledge:

I've built a five year course - when people say an apprenticeship, (normally) it's two years. I've been absolutely saddened by the attitude of the industry where it is encouraged and rewarded to collect as many apprentices as you can, massive intake then after two years, you take an eighteen year old and you say: I'm sorry there's no future with us.... The driving force for us is, you pass and do your apprenticeship with us and you are guaranteed a career. That's part of the deal... you work hard for me, you work hard for the business and we will look after you and we will guarantee you a framework.

Within Simon's contribution there is an explicit criticism of some other employers' attitudes to the New Apprenticeships and indeed, evidence is emerging that the new scheme is not fulfilling expectations (Richmond 2018). Simon's non-exploitative approach is distinctive and, in the TTL experiences on offer through his model of apprenticeship, he seeks to connect the success of his company with the personal development of employees. In his case, there is space alongside the learner and the teacher on the 'driving seat' and his is an enabling rather than a dominant role.

\section{Conclusions}

The research this article is based on sees us beginning to theorise TTL as an approach to teaching and learning that foregrounds the students' interests above the interplay of competing forces and contextual considerations in further education. Our claim is not that all teaching and learning in further education colleges can be described as transformative but rather, that despite hegemonic structures and cultures (broadly underpinned by government policy) that incentivize a triple-lock of student objectification, TTL is still taking place. It is important that this objectification is not under-stated. It equates to a compromising and an undermining of human dignity. Indeed, the notion of objectification has further ramifications linked to dehumanization. In a discussion about the instrumentalisation of people and the implications of 'the use of a person', Kaufman (2011) makes important points about what this means for their human dignity. If we subscribe to a belief in human dignity, that is, the inherent worth of all individuals (and policy documents that address social justice and equality suggest our current government does) then that must proscribe us from weighing the value of the individual in an algorithm of goods and values. Yet, the triple-lock concept suggests that behind the further educational relationship between students and teachers lurks calculation and monetisation and (most importantly) that this has the potential to undermine any educational relationship that is founded on the safeguarding and enhancement of students' human dignity.

The cumulative effect of the triple-lock of objectification might be hidden (and even trivialized) by the use of the term 'gaming' (see Wolf 2011) to denote the practices some institutions engage in in response to the marketised structures that underpin further education. It may also obscure the cultures that arise as a consequence of this. An example of this might be the prevalence of the term 'bums on seats' (Smith 2007) that appears to both signal and be complicit in a culture of institutionalized objectification. Interestingly, there is also an implied diminution of the educator in the use of such a term that is traceable back to 
the commodifying influence of marketization. Just as the risk inherent in this system reduces students to 'bums on seats', so, it also risks reducing teachers to salespeople.

The objectification of students is not ameliorated by the achievement of a qualification if, as pointed out by Wolf (2011) and (regarding apprenticeships) Fuller and Unwin (2015) and Richmond (2018), students are put on qualifications to meet the financial interests of providers / employers. The transformative aspects of TTL can be seen as consciously operating against the grain of commodification while keeping it in view. TTL works against reducing educational relationship to the transactional. Current funding arrangements have institutionalised objectification and made the taking away of students' human dignity a structural feature of the further education system. From this discussion we can conclude that TTL environments operate in order to enhance the human dignity of students and staff alike. Or, put another way, TTL environments are those in which the forces conducive to objectification, those exemplified by the triple-lock, are most effectively kept at bay. It follows that teachers in further education settings whose practice exemplifies TTL are not focused on contributing to the British economy, or on labelling their students as second-class and 'unacademic' or even on thinking about how their efforts will contribute to college coffers; rather they get up because they live and work to interact with students, see them learn and grow to become independent users of knowledge and skills as their educational identities connect with their hopes for life and work in the future. In other words, TTL is characterised by the absence of 'use' and its replacement with consent and a cooperative engagement in the collective project of further education.

\section{References}

Ade-Ojo, G. and Duckworth, V. (2015) Adult Literacy Policy and Practice: From Intrinsic Values to Instrumentalism. Palgrave Macmillan Pivotal: London

Ade-Ojo, Gordon and Duckworth, V. (2016) Of cultural dissonance: the UK's adult literacy policies and the creation of democratic learning spaces. International Journal of Lifelong Education. pp. 1-18

Ball, S. (2017) The Education Debate. Bristol: Policy Press

Becker, Gary, S. 1993. Human Capital, A theoretical and empirical analysis with special reference to education. London: University of Chicago Press.

Biesta, G. J. J. 2010. Good education in an age of measurement: Ethics, politics, democracy. Boulder, Co: Paradigm Publishers.

Biesta, G. J. J. 2-16. The Rediscovery of Teaching: On robot vacuum cleaners, non-egological education and the limits of the hermeneutical world view. Educational Philosophy and Theory, 48: 4, 374-392.

Boden, R. \& Nedeva, M. 2010. 'Employing discourse: Universities and graduate employability'. Journal of Education Policy, 25: 37 - 54.

Bourdieu, P. and Passeron, J-C. 2013. Reproduction in Education, Society and Culture. London: Sage.

Braun, V. and Clarke, V. 2006. Using thematic analysis in psychology. Qualitative Research in Psychology. 3 77-101.

Brookfield, S. 2005. Becoming a Critically Reflective Teacher. San Francisco: Jossey Bass. Coffield, F. 2008. Just suppose teaching and learning became the first priority... Learning and Skills Network. 
http://weaeducation.typepad.co.uk/wea education blog/files/frank coffield on teach and learning.pdf. 09.03.18.

Department for Business, Innovation and Skills (BIS) / HM Treasury. 2015. Fixing the

Foundations: creating a more prosperous nation.

https://www.gov.uk/government/publications/fixing-the-foundations-creating-a-more-

prosperous-nation. Accessed 15.08.17.

Department for Education (DfE) 2015. Provisional GCSE and equivalent results in England, 2014 to 2015.

https://assets.publishing.service.gov.uk/government/uploads/system/uploads/attachment data/file/46

7603/SFR37 2015.pdf. Accessed 08.04.18.

Department for Education (DfE) 2017. Provisional GCSE and equivalent results in England, 2016 to 2017.

https://assets.publishing.service.gov.uk/government/uploads/system/uploads/attachment_d ata/file/653532/SFR57 2017.pdf. Accessed 28.03.18.

Department for Education and Employment (DfEE) 1998. The Learning Age: A Renaissance for a New Britain (Green Paper CM 3790). London: The Stationery Office.

Department for Education and Skills (DfES) 2002. Success for All. London: DfES.

Duckworth, V. 2013. Learning Trajectories, Violence and Empowerment amongst Adult Basic Skills

Learners. Research in Education. London: Routledge

Duckworth, V. 2014. 'Literacy and Transformation'. In Duckworth, V. and Ade-Ojo, G.

(eds.) Landscapes of Specific Literacies in Contemporary Society: Exploring a social model of literacy. Routledge Research in Education: London. 27 - 46.

Duckworth, V. \& Smith, R. 2017a. Further education in England - Transforming lives and communities: Interim Report. UCU

http://transforminglives.web.ucu.org.uk/2017/01/19/further-education-in-england-

transforming-lives-and-communities/

Duckworth, V and Smith R. 2017b. UCU research transforming lives and communities.

A national practitioner guidance booklet is being developed with a focus on transformative education.

http://transforminglives.web.ucu.org.uk/2017/06/05/sharing-transformational-approachesto-teaching-and-learning/

Duckworth, V. and Smith, R. 2018. Women, adult literacy education and transformative bonds of care, Australian Journal of Adult Learning. Forthcoming.

Feeley, M. 2007. Adult Literacy and Affective Equality: Recognising the Pivotal Role of Care in the Learning Relationship. Dublin University: unpublished PhD.

Freire, P. 1996. Pedagogy of the Oppressed. London: Penguin.

Fuller, A. 2011. "What about the majority? Rethinking post-16 opportunities". In National Skills Forum. 2011. Open to Ideas. Essays on education and Skills. London: Policy Connect. 5659.

Goodson, I. F. and Sikes, P. 2001. Life History Research in Educational Settings: Learning from Lives. Buckingham: Open University Press.

Grek, S. (2008) 'From symbols to numbers: the shifting technologies of education governance in Europe', European Education Research Journal, 7(2), 208-218.

Illeris, K. 2013. Transformative Learning and Identity. London: Routledge.

Kaufman, P. 2011. “Instrumentalisation: What does it mean to use a person?" In Kaufman, P. Kuch, H., Neuhauser, C. and Webster, E. 2011. Humiliation, Degradation, Dehumanisation Human Dignity Violated. London: Springer. 
Lather, P. 1991. Getting Smart. London: Routledge.

Lefebvre, H. 1991. The production of space. Oxford: Blackwell.

Mansell, W. 2007. Education by Numbers: The Tyranny of Testing. London: Politico.

Mezirow, J. 1990. Fostering Critical Reflection in Adulthood, San Francisco: Jossey-Bass.

O'Leary, M. \& Smith, R. 2012. Earthquakes, cancer and cultures of fear: qualifying as a Skills for Life teacher in an uncertain economic climate, Oxford Review of Education. 38:4, 437-454.

OECD. 2017. Compendium of Productivity Indicators. http://www.oecd.org/std/productivitystats/oecd-compendium-of-productivity-indicators-22252126.htm. 30.08.17.

Nowell, L. S., Norris, J. M., White, D.E. and Moules N.J. . 2017. Thematic analysis: striving to meet the trustworthiness criteria. International Journal of Qualitative Methods. 16:1. 1-13.

Payne, J. 2000. The unbearable lightness of skill: the changing meaning of skill in UK policy discourses and some implications for education and training, Journal of Education Policy, 15:3, 353-369.

Petras, J. 2000. The Third Way: Myth and Reality. The Monthly Review. 51: 10.

https://monthlyreview.org/2000/03/01/the-third-way/. 30.08.17.

Richmond, T. 2018. The great training Robbery. Assessing the first year of the Apprenticeship Levy. http://www.reform.uk/publication/the-great-training-robbery-assessing-the-first-year-of-theapprenticeship-levy/. Accessed 12.04.18.

Rocks, E. \& Lavender, P. 2018. Exploring Transformative Journeys through a Higher Education Programme in a Further Education College, Journal of Education and Training, Smith, R. \& O'Leary, M. 2013. New Public Management in an age of austerity: knowledge and experience in further education, Journal of Educational Administration and History, 45:3, 244-266.

Schon, D. 1983. The Reflective Practitioner. London: Temple Smith.

Smith, R. 2007. Work, Identity and the Quasi-market: The FE Experience, Journal of Educational Administration and History, Special Practitioners' Research Edition, 39: 1, 33-47. Smith, R. 2017. Area Reviews and the end of incorporation: A Machiavellian moment. In Daley, M., Orr, K. and Petrie, J. 2017. The Principal. London: UCL IoE Press.

Stenhouse, L. 1981. 'What Counts as Research?' British Journal of Educational Studies. 29: 2. 103-114.

Thomas, G. \& James, D. 2006. Reinventing grounded theory: some questions about theory, ground and discovery, British Educational Research Journal, 32:6, 767-795.

Thompson, S., Colebrook, C., Hatfield, I. and Doyle, P. 2016. Boosting Britain's low-wage sectors a strategy for productivity, innovation and growth. Institute for Public Policy Research. https://www.ippr.org/files/publications/pdf/low-wage-sectors May2016.pdf. 30.08.17.

Thompson, R. 2009. Social class and participation in further education: evidence from the Youth Cohort Study of England and Wales. British Journal of Sociology of Education. 30:1, 2942.

UK Commission for Employment and Skills (UKCES) 2009. Ambition 2020: world class skills and jobs for the UK.

http://webarchive.nationalarchives.gov.uk/+/http:/www.ukces.org.uk/PDF/UKCES FullRep ort USB A2020.pdf. 30.08.17.

University and College Union (UCU). 2015. UCU briefing on $24 \%$ cuts to adult further education budget in England.

https://www.ucu.org.uk/media/7108/FE-England-budget-cuts-2015-16---a-UCU-

briefing/pdf/ucu fecutsbriefing feb15.pdf. 25.08.17.

Wolf, A., 2011. Review of vocational education - the Wolf report. 
https://www.gov.uk/government/uploads/system/uploads/attachment data/file/180504/DFE -00031-2011.pdf. 17 August 2017. 